\title{
Fatigue Failure Analysis on Precracked 304 Stainless Steel Components Repaired by Laser with Addition of Nanocomposites
}

\author{
Jie Wang ${ }^{1}$, Wei Jiang ${ }^{1}$ (D) \\ ${ }^{1}$ Dalian University of Technology, School of Mechanical Engineering, Dalian, P. R., China.
}

How to cite: Wang J, Jiang W. Fatigue failure analysis on precracked 304 stainless steel components repaired by laser with addition of nanocomposites. Soldagem \& Inspeção. 2019;24:e2408. https://doi.org/10.1590/0104-9224/SI24.08

\begin{abstract}
The service life of components can be extended by repairing fatigue crack with laser so as to improve resource utilization rate. However, the effect of laser repair may be influenced by the instability of laser treatment. To investigate the addition of nanocomposites on the laser repairing effect, fatigue test under uniaxial tension was carried out to evaluate the fatigue life of precracked 304 stainless steel components repaired by laser. According to the results obtained from fatigue tests, a probabilistic fatigue life distribution model considered the sampling size and discreteness of data was established based on the three-parameter Weibull distribution model and three-parameter stress-life equation. The results of probabilistic fatigue life distribution model show that the fatigue life of components repaired by laser with addition of WC nanocomposites can be enhanced significantly, especially the high cycle fatigue life. Moreover, the microstructure of repaired region show that the WC nanoparticles could refine the recrystallized grains and lead to the improvement of strength and toughness of material around crack tip, which are the main reason of improved fatigue life. Meanwhile, smooth surface of repaired region caused by WC nanoparticles can also prevent the initiation of microcracks.
\end{abstract}

Key-words: Fatigue failure; Laser repair; WC nanocomposites; Microstructure.

\section{Introduction}

The fatigue failure of components under cyclic loading consists of two phases including the crack initiation and extension to ultimate fracture. The initiation of cracks occupies a large part in the process of fatigue failure, which has a significance influence on fatigue life of components. For cracked components, taking certain measures to suppress the further extension of cracks can prolong the service life of components. It has a positive effect on improving resource utilization rate and environmental protection. At present, there are many methods can be used to suppress crack propagation, including stop-crack holes, penetration composite materials, bonding repair of composite materials, welding repair etc [1]. Many studies have shown that laser peening (LP) can remarkably enhance the fatigue strength of alloys [2-5]. Ren et al. [6] investigated the mechanical properties of 00Cr12 alloy at high temperatures altered by laser shock processing (LSP). The results show that compressive residual stress introduced by LSP has a significant effect on fatigue enhancement. Zhang et al. [7] investigated the order of magnitude diminution in the fatigue crack growth rates of an epoxy system with addition of a small amount of carbon nanotubes. The pullout carbon nanotubes bridges the crack interface and can cause the crack to be arrested. Jiang and Jiang [8] carried out the laser repair experiments of cracked 304 stainless steel (304SS). The experimental results showed that the COD (Crack Opening Displacement) of compact tension specimen repaired by laser with addition of nanocomposites reduced to a certain extent. Meso-damage mechanics show that the internal structure of the material has random distribution behavior, such as lattice defects, impure atoms, size of sliding crystals, grain boundary parameters, macro porosity, crack and machining defects $[9,10]$. Therefore, the internal damage of material is random. There are various random factors in the process of nucleation, growth and coalescence of microcracks, which result in the dispersion of fatigue life. As a scientific method of structural fatigue life assessment, the fatigue reliability analysis based on probability $S-N$ curve is widely used in engineering. This analysis method is mainly based on random concepts and statistical methods to study the distribution law of fatigue life under a specific survival probability [11-13]. The probabilistic stress-life curve is constructed base on the qualitative $S-N$ relation model such as Basquin equation, three parameter equation and Langer equation. The conventional maximum likelihood method are also used to establish the reliability statistical model of grouped or all fatigue life data related to the load level [14]. The $S-N$ relation model considered the dispersion rule and error risk is usually referred to as probabilistic

Received: 08 Sept. 2018. Accepted: 31 Mar., 2019.

E-mail: jiangwei@dlut.edu.cn (JW)

This is an Open Access article distributed under the terms of the Creative Commons Attribution Non-Commercial License which permits unrestricted non-commercial use, distribution, and reproduction in any medium provided the original work is properly cited. 
fatigue $P-C-S-N$ curve related to survival probability $P$ and confidence $C$ [10]. The main statistical methods for sample data include logarithmic distribution, normal distribution, Weibull distribution etc.

In order to study the effect of WC nanoparticles on fatigue crack initiation and improvement of fatigue life, the fatigue test of compact tension specimen repaired by laser was first carried out and the required cycles for crack initiation was recorded. Then, the fatigue life distribution model of laser repaired compact tension specimen (CT) was established based on probabilistic $S-N$ curves in which the three-parameter Weibull distribution model was applied to statistics of sample data. The confidence limit analysis was adopted to ensure the rationality of fatigue life distribution model. Finally, combined with the microstructure of repaired area, the mechanism for extending fatigue life of laser repair with addition of WC nanocomposites was analyzed in terms of grain boundary strengthening. The probabilistic fatigue life distribution models obtained by reliability design method can provide reference for the assessment of fatigue performance of cracked component repaired by laser.

\section{Material and Experiment Methods}

\subsection{Experiment material}

The 304 stainless steel (304SS) is widely used in chemical industry, automotive, and nuclear industries for reactor coolant piping, marine region, value bodies, and vessel internals due to its outstanding mechanical properties and it can be easily formed and welded. The 304SS was used to make CT specimen. The chemical composition 304SS is listed in Table 1 . The CT specimen was designed in accordance with ASTM E647-2013a Standard Test Method for Measurement of Fatigue Crack Growth Rates [15], as shown in Figure 1. The nanocomposite powder used in the repairing experiment is composed of nano WC particles and 304SS particles and their mass fraction are 5\% and 95\%, respectively. Powder ingredients of 304 SS are selected similar to those of the specimen, as listed in Table 1. The size of WC particle is about 50nm and the size of 304SS particle is about 30-50 $\mu \mathrm{m}$. The morphology of these two powders can refer to reference [8]. To prevent agglomeration of nano WC particles in the preparation of mixed powders, all powders were blended and milled by using ceramic mortar at room temperature and anhydrous alcohol was added as dispersant. The milling was finished when the anhydrous alcohol evaporates completely and repeat this operation to ensure a uniform dispersion.

Table 1. Chemical composition of 304SS (wt.\%).

\begin{tabular}{ccccccccccc}
\hline Composition & C & Si & Mn & P & S & Cr & Ni & Mo & Fe \\
304SS substrate & 0.033 & 0.480 & 1.324 & 0.037 & 0.005 & 19.500 & 7.370 & 0.313 & Bal \\
304SS powder & 0.08 & 0.50 & 1.46 & 0.03 & 0.005 & 19.00 & 9.50 & 0.5 & Bal \\
\hline
\end{tabular}
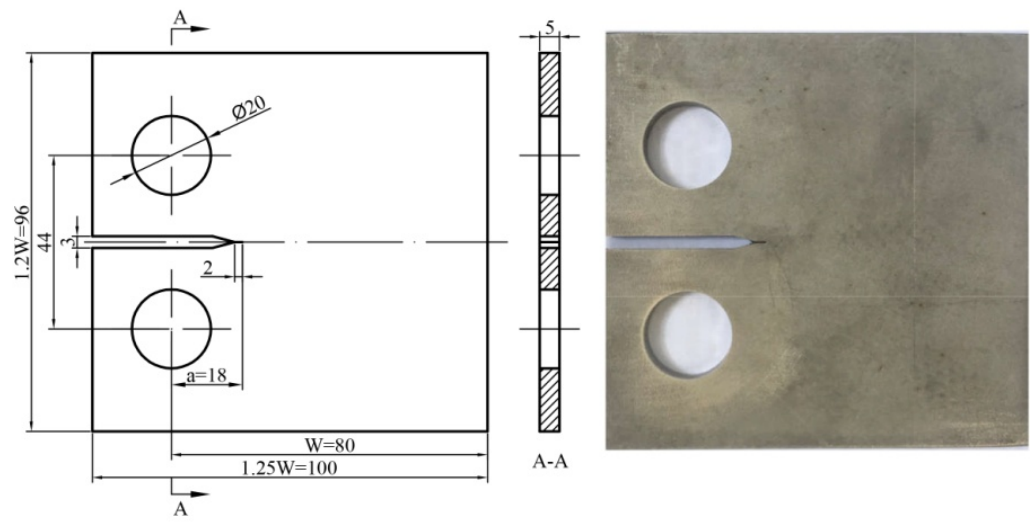

Figure 1. The dimensions of CT specimen.

\subsection{Experiment methods}

The DL-HL-T5000B type transverse flow $\mathrm{CO}_{2}$ laser with the power of $5 \mathrm{~kW}$ was used in laser repair experiments. The processing parameters of laser in the repair experiment are as follows: laser power is $1800 \mathrm{~W}$, the laser beam spot is $3 \mathrm{~mm}$, and the defocus distance is $10 \mathrm{~mm}$. Before the laser repair experiment, the sandpaper with a granularity of $400-2000$ was used to polish the surface of repaired region to remove oxide layer and the surface was cleaned with anhydrous ethanol. Then the dried composite nano powder with a thickness of $1 \mathrm{~mm}$ was preset on the repair region. 
As shown in Figure 2a, MTS 810 Material Test System was employed in fatigue test, the frequency is $20 \mathrm{~Hz}$ and the load ratio is 0.1 . Only one side of the sample was repaired by laser, another side was used to check fatigue failure of specimen. The fatigue failure criterion is the initiation of micro cracks with a length of $1.5 \mathrm{~mm}$ at the tip of prefabricated crack, as shown in Figure $2 \mathrm{~b}$. The length of crack is measured by a measuring microscope and 10 sets of test were conducted at each load level. The fatigue life corresponding to crack with a length of $1.5 \mathrm{~mm}$ may not be measured directly, so it was obtained by linear interpolation of two adjacent measuring data of which the crack length are greater than and less than $1.5 \mathrm{~mm}$, respectively.

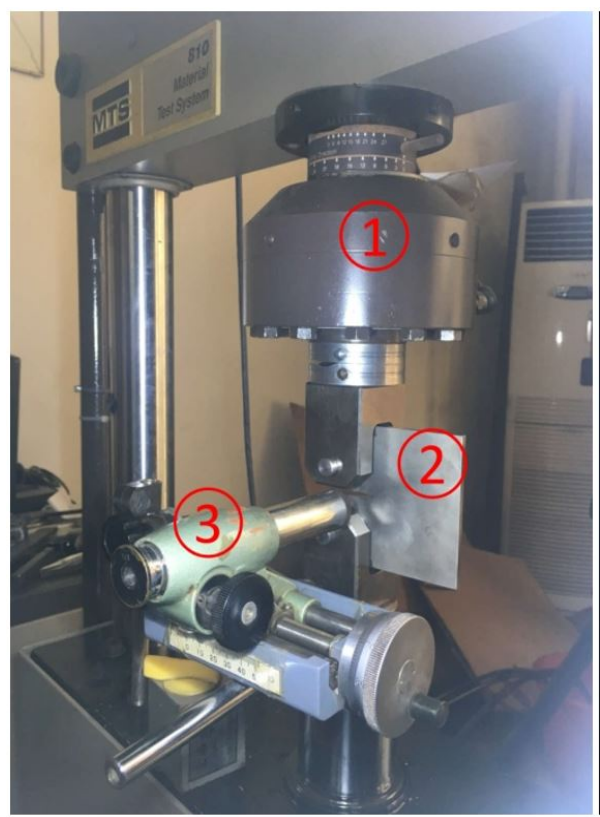

(a)

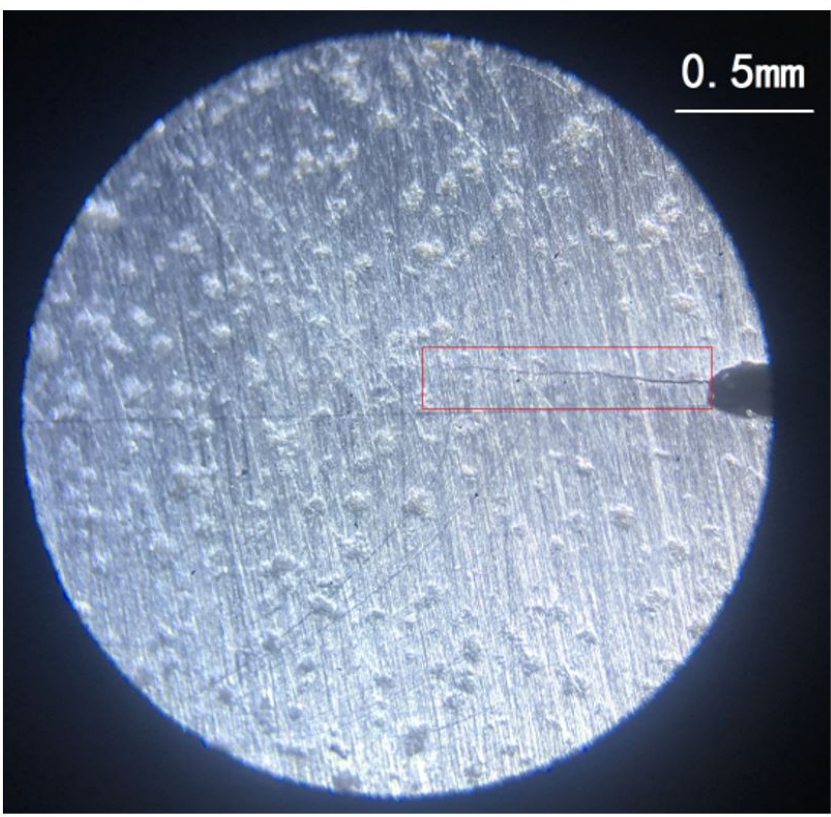

(b)

Figure 2. Experimental equipment and dimension of specimen. (a) Material test system: 1 . MTS 810 material test system; 2 . CT specimen; 3. measuring microscope; (b) Enlarged view of microcrack.

\section{The Establishment of Probabilistic S-N Curves}

\subsection{Distribution model of fatigue life}

Assuming that the fatigue life $N$ at any load level $S_{c a}$ obeys the statistical model of three parameters Weibull distribution, the expression is

$$
P\left(N \mid S_{c a}\right)=1-\exp \left[-\left(\frac{N-\mu}{\sigma}\right)^{m}\right]
$$

in which, $P\left(N \mid S_{c a}\right)$ is the failure probability; $\mu$ is position parameter, that is, the threshold value of failure; $m$ is shape parameter, which are used to describe the dispersivity of measured data; $\sigma$ is scale parameter related to the average value of measured data.

Twice logarithmic transform was carried out to rearrange the Equation 1, as shown in the following Equation 2.

$\operatorname{In}\left(\operatorname{In}\left(\frac{1}{1-P\left(N \mid S_{c a}\right)}\right)\right)=m \operatorname{In}(N-\mu)-m \operatorname{In}(\sigma)$

If the confidence $C$ related to the sample size $n_{s}$ was considered, the probabilistic fatigue life can be determined by Equation 3 after the point estimation of fatigue life $N$ and corresponding Weibull statistical parameters including $m, \mu$ and $\sigma$ were obtained. 


$$
\operatorname{In}\left(N_{P-C}-\mu\right)=\frac{1}{m} \operatorname{In}\left(\operatorname{In}\left(\frac{1}{1-P\left(N \mid S_{c a}\right)}\right)\right)+\operatorname{In}(\sigma)+\delta_{1-C}\left(n_{s}\right)
$$

in which, $N_{P-C}$ is fatigue life with a specified $P-C$ set; $\delta_{1-C}\left(n_{s}\right)$ is a statistical function of error of Equation 3 describing the test data $S_{c a}-N$ at a confidence of $C$.

\subsection{Generalized description of probabilistic $\mathbf{S}-\mathbf{N}$ curves}

The Langer, Basquin and three parameter stress-life models can be unified as

$\left(S_{c a}-S_{0}\right)^{\alpha} N=\beta$

in which $S$ is loading level; $N$ is fatigue life; $S_{O}, \alpha$ and $\beta$ are material constants. This equation is a three parameters model. It can be converted into Basquin stress-life model for $S_{0}=0$ and Langer model for $\alpha=2$.

The Equation 5 can be obtained through the logarithmic transformation of Equation 4, and the symbol $l g$ defaults to base-10 logarithm.

$\lg N=\lg \beta-\alpha \lg \left(S_{c a}-S_{0}\right)$

By considering the statistical effect related to the size $n$ and dispersion of fatigue life $N$, the probability fatigue $P-C-S_{c a}-N$ curve can be expressed as shown in Equation 6.

$\lg N_{P-C}=\lg \beta_{P-C}-\alpha_{P-C} \lg \left(S_{c a}-S_{0, P-C}\right)$

where $P-C$ is combined survival probability and confidence set; $\beta_{P-C}, \alpha_{P-C}$ and $S_{0, P-C}$ are material constants which are obtained by fitting the $S_{c a}-N_{P-C}$ data.

\subsection{The introduction of reliability estimation methods}

Fatigue tests under load level $S_{c a}$ were carried out by group method. There are $m$ load levels and the number of samples at ith load level are $n_{i}$. Arrange the fatigue life under load level $S_{c a i}$ from small to large, as shown in Equation 7.

$x_{1}<x_{2}<\cdots x_{k-1}<x_{k} \cdots<x_{n i-1}<x_{n i}$

Cumulative probability density function $F\left(x_{k}\right)$ of fatigue lifetime datum $x_{k}$ is the failure probability of $k$ th datum. So, its reliability can be expressed as $P\left(x_{k}\right)=1-F\left(x_{k}\right)$. Reliability can be estimated by medium rank method via Equation 8 .

$P\left(x_{k}\right)=1-\frac{k-0.3}{n_{i}+0.4}$

The data $N_{i k}-P_{i k}$ under each load level were assumed to obey the three parameter Weibull distribution and can be determined via above formula. Substituting the data $N_{i k}-P_{i k}$ into Equation 3 and the coefficients were subsequently determined through the method of linear fitting, the detailed solution is shown as follows

Rearrange the Equation 2 to the form of $y=A+B x$, in which, $y=\operatorname{In}\left(\operatorname{In}\left(\frac{1}{1-P\left(N_{i k} \mid S_{c a i}\right)}\right)\right), x=\operatorname{In}(N-\mu), A=m, B=-m \operatorname{In}(\sigma)$.

Parameters A and B can be estimated by least squares fitting as shown in the following Equation 9 and Equation 10.

$A=\frac{1}{n} \sum_{j=1}^{n_{i}} y_{j}-B \frac{1}{n} \sum_{j=1}^{n_{i}} x_{j}$ 


$$
B=\frac{\sum_{j=1}^{n_{i}} x_{j} y_{j}-\frac{1}{n}\left(\sum_{i=1}^{n_{i}} x_{j}\right)\left(\sum_{j=1}^{n_{i}} y_{j}\right)}{\sum_{j=1}^{n_{i}} x_{j}^{2}-\frac{1}{n}\left(\sum_{j=1}^{n_{i}} x_{j}\right)^{2}}
$$

The value of $\mu$ can be estimated by one-dimension search method and the searching interval can be determined according to the desired accuracy. Normally the value range of $\mu$ is $\left[0, N_{\min }\right), N_{\min }$ is the minimum value of $N_{i}$. It can be assumed that the initial value of $\mu$ is 0 . The iterative solution was used until the maximum value of correlation coefficient $r$ was obtained to ensure the best fitting effect. The expression of $r$ is shown in Equation 11.

$$
r=\frac{\sum_{j=1}^{n}\left(P_{j} P_{j}^{\prime}-n \bar{P} \bar{P}^{\prime}\right)}{\sqrt{\left(\sum_{j=1}^{n} P_{j}^{2}-n \bar{P}^{2}\right)\left(\sum_{j=1}^{n} P_{j}^{\prime 2}-n \bar{P}^{\prime 2}\right)}}
$$

where the $P^{\prime}$ is calculated by the Equation 1 in which the parameters are obtained via current fitting. Figure 3a and Figure $3 \mathrm{~b}$ are showing the test results of change of correlation coefficient with the location parameter of this paper. Through comprehensive analysis of results shown in figures, we can conclude that the position parameter has a certain effect on the fitting error of most data and the fitting error can be reduced by using the one-dimensional search method.

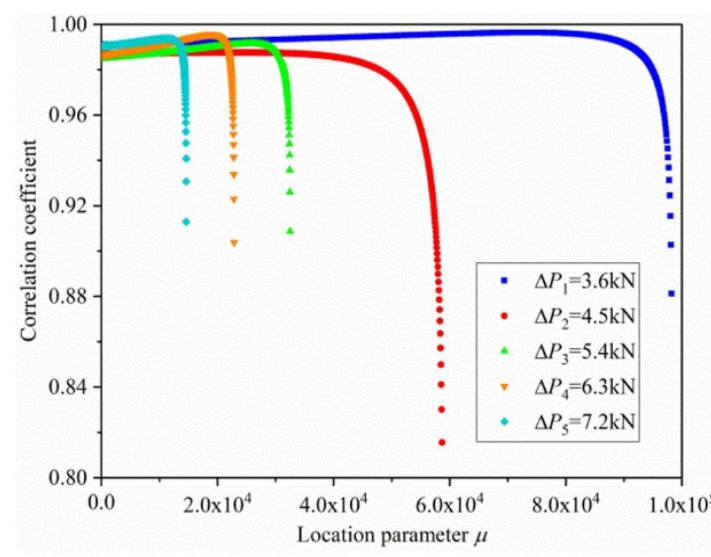

(a)

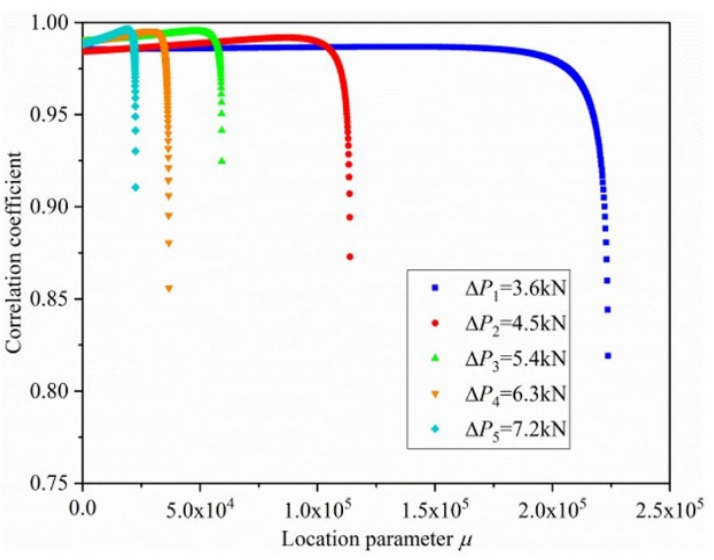

(b)

Figure 3. Variation of correlation coefficient in one dimension search process. (a) Laser repair only; (b) Laser repair with addition of nanocomposite powder.

\subsection{Parameters determination of confidence}

According to the method proposed by Zhao and Liu [16], the confidence interval of probabilistic fatigue $S-N$ curve can be determined, the statistical error function $\delta_{1-C}\left(n_{s}\right)$ in Equation 3 can be expressed as following Equation 12.

$\delta_{l-C}\left(n_{s}\right)=t_{l-C}\left(n_{s}-2\right) s_{r} \sqrt{1+\frac{1}{n_{s}}}$

where $t_{l-C}\left(n_{s}-2\right)$ is the t-distribution function at a significance level of $1-C$ with a degree-of-freedom of $n_{s}-2 ; s_{r}$ is the residual standard deviation of Equation 3 by fitting the $S_{c a i}-N_{i}$ data, which can be defined by following Equations 13, 14, 15, 16, 17 and 18.

$s_{r i}=\sqrt{\frac{1}{n_{i}-2} \frac{L_{X X i} L_{Y Y i}-L_{X Y i}^{2}}{L_{X X i}}}$ 


$$
\begin{aligned}
& L_{X X i}=\sum_{k=1}^{n_{s}}\left(X_{i k}-X_{\text {iav }}\right)^{2} \\
& L_{Y Y i}=\sum_{k=1}^{n_{i}}\left(Y_{i k}-Y_{\text {iav }}\right)^{2} \\
& L_{X Y i}=\sum_{k=1}^{n_{i}}\left(X_{i k}-X_{\text {iav }}\right)\left(Y_{i k}-Y_{i a v}\right) \\
& X_{\text {iav }}=\frac{1}{n_{i}} \sum_{k=1}^{n_{i}} X_{i k} \\
& Y_{\text {iav }}=\frac{1}{n_{i}} \sum_{k=1}^{n_{i}} Y_{i k}
\end{aligned}
$$

\subsection{Parameters determination of probability S-N curve}

The Equation 7 are rearranged in the form of $y=A+B x$ as shown in below Equation 19:

$\lg N_{P-C}=-\alpha_{P-C}+\lg \beta_{P-C} \cdot \lg \left(S_{c a}-S_{0, P-C}\right)$

in which $y=\lg N_{P-C}, \quad x=\lg \left(S_{c a}-S_{0, P-C}\right), \quad A=-\alpha_{P-C}, \quad B=\lg \beta_{P-C}$. When the constant of the Weibull distribution model were determined, the value of $N_{P-C}$ can be estimated by Equation 3. Parameters $\mathrm{A}$ and $\mathrm{B}$ can be estimated by least squares fitting as described in Section 3.4. Then, the material constants $\alpha_{P-C}$ and $\beta_{P-C}$ can be determined accordingly. The value of $S_{O, P-C}$ can also be determined by one-dimensional search method to ensure the maximum correlation coefficient could be obtained.

\section{Test Results and Discussion}

\begin{tabular}{|c|c|c|c|}
\hline No. & \multicolumn{2}{|c|}{ Load amplitude (N) } & Cycles \\
\hline \multirow{2}{*}{1} & \multirow{2}{*}{3600} & RLWNP & $223969,272367,286143,294206,307681,330031,358528,361605,363052,419484$ \\
\hline & & RLO & $98309,117816,127877,143843,149979,167946,178772,184088,215410,250784$ \\
\hline \multirow{2}{*}{2} & \multirow{2}{*}{4500} & RLWNP & 113933, 132204, 152820, 162765, 172525, 176492, 197026, 200861, 239210, 269679 \\
\hline & & RLO & $58768,85103,90700,96341,99392,107441,126596,130719,137663,153250$ \\
\hline \multirow{2}{*}{3} & \multirow{2}{*}{5400} & RLWNP & $59335,64832,70956,73904,84484,90970,97711,100205,111347,133404$ \\
\hline & & RLO & $32531,35297,40778,41048,47673,49168,50185,58135,62814,68785$ \\
\hline \multirow{2}{*}{4} & \multirow{2}{*}{6300} & RLWNP & $36746,43815,47142,48258,52443,53945,57767,63661,66476,73942$ \\
\hline & & RLO & $22866,25708,28985,32867,35352,32399,39904,41394,48547,54545$ \\
\hline \multirow{2}{*}{5} & \multirow{2}{*}{7200} & RLWNP & $22523,25463,27484,28363,31908,35000,36041,38500,43318,49907$ \\
\hline & & RLO & 14619, 16912, 17989, 20221, 22707, 25252, 28908, 30398, 31503, 38601 \\
\hline
\end{tabular}

The results of fatigue test are given in Table 2. There are five load levels. The number of samples under each load are ten. RLO denotes the specimen was repaired by laser only, RLWNP denotes the specimen was repaired by laser with the addition of nanocomposite powder.

Table 2. Fatigue test results.

According to the method mentioned in Section 3.3, the fatigue life samples under each load level follows the three parameter Weibull distribution and corresponding parameters can be determined, as shown in Table 3. 
Table 3. Parameter values of three parameters Weibull distribution.

\begin{tabular}{|c|c|c|c|c|c|c|}
\hline & Load(N) & 3600 & 4500 & 5400 & 6300 & 7200 \\
\hline \multirow{2}{*}{$\mu$} & RLWNP & 136396 & 86816 & 48357 & 28551 & 19099 \\
\hline & RLO & 73240 & 22978 & 25862 & 18750 & 11183 \\
\hline \multirow{2}{*}{$\sigma$} & RLWNP & 207253 & 109030 & 46197 & 29642 & 16924 \\
\hline & RLO & 103537 & 96716 & 26168 & 20106 & 15526 \\
\hline \multirow{2}{*}{$m$} & RLWNP & 3.2842 & 1.9667 & 1.7433 & 2.2094 & 1.6725 \\
\hline & RLO & 1.9175 & 2.9135 & 1.8581 & 1.6792 & 1.6957 \\
\hline \multirow{2}{*}{$r$} & RLWNP & 0.9868 & 0.9918 & 0.9950 & 0.9955 & 0.9962 \\
\hline & RLO & 0.9964 & 0.9876 & 0.9914 & 0.9956 & 0.9936 \\
\hline
\end{tabular}

According to the method described in Section 3.5, we can determine the probability $S$ - $N$ curve under specified confidence $C$ and survival probability $P$ and related material parameters are given in Table 4 .

Table 4. Parameter values of S-N curves.

\begin{tabular}{|c|c|c|c|c|c|c|c|c|}
\hline \multirow{2}{*}{$\begin{array}{c}\text { Confidence } \\
\qquad \text { C (\%) }\end{array}$} & \multirow{2}{*}{$\begin{array}{c}\text { Probability } \\
\text { P }\end{array}$} & \multirow{2}{*}{ Confidence limit } & \multicolumn{2}{|c|}{$\alpha_{P-C}$} & \multicolumn{2}{|c|}{$\beta_{P-C}(\mathrm{Ig})$} & \multicolumn{2}{|c|}{$S_{0, P-C}$} \\
\hline & & & RLWNP & RLO & RLWNP & RLO & RLWNP & RLO \\
\hline \multirow{6}{*}{90} & \multirow{2}{*}{0.5} & Upper limit & 3.30 & 2.85 & 17.2565 & 15.3487 & 0 & 0 \\
\hline & & Lower limit & 3.37 & 2.87 & 17.5348 & 15.4443 & 0 & 0 \\
\hline & \multirow{2}{*}{0.95} & Upper limit & 3.13 & 2.75 & 16.7877 & 15.1788 & 0 & 0 \\
\hline & & Lower limit & 3.20 & 2.75 & 17.0753 & 15.2328 & 0 & 0 \\
\hline & \multirow{2}{*}{0.99} & Upper limit & 3.05 & 2.70 & 16.5513 & 15.0576 & 0 & 0 \\
\hline & & Lower limit & 3.12 & 2.70 & 16.8408 & 15.1013 & 0 & 0 \\
\hline \multirow{6}{*}{95} & \multirow{2}{*}{0.5} & Upper limit & 3.29 & 2.85 & 17.2122 & 15.3327 & 0 & 0 \\
\hline & & Lower limit & 3.38 & 2.87 & 17.5828 & 15.4598 & 0 & 0 \\
\hline & \multirow{2}{*}{0.95} & Upper limit & 3.12 & 2.75 & 16.7417 & 15.1696 & 0 & 0 \\
\hline & & Lower limit & 3.21 & 2.75 & 17.1245 & 15.2415 & 0 & 0 \\
\hline & \multirow{2}{*}{0.99} & Upper limit & 3.04 & 2.70 & 16.5049 & 15.0501 & 0 & 0 \\
\hline & & Lower limit & 3.13 & 2.70 & 16.8902 & 15.1083 & 0 & 0 \\
\hline \multirow{6}{*}{99} & \multirow{2}{*}{0.5} & Upper limit & 3.27 & 2.84 & 17.1151 & 15.2966 & 0 & 0 \\
\hline & & Lower limit & 3.41 & 2.88 & 17.6921 & 15.4945 & 0 & 0 \\
\hline & \multirow{2}{*}{0.95} & Upper limit & 3.09 & 2.75 & 16.6402 & 15.1487 & 0 & 0 \\
\hline & & Lower limit & 3.24 & 2.76 & 17.2363 & 15.2608 & 0 & 0 \\
\hline & \multirow{2}{*}{0.99} & Upper limit & 3.01 & 2.70 & 16.4025 & 15.0332 & 0 & 0 \\
\hline & & Lower limit & 3.16 & 2.70 & 17.0025 & 15.1238 & 0 & 0 \\
\hline
\end{tabular}

Results of the present probabilistic $S-N$ model are given in Table 4. The probabilistic $S-N$ curves can reveal the statistical effect of sample size and dispersion. Take one set of data as an example, test data and probabilistic $S-N$ curves with $C=99 \%$ at specified $P$ levels are exhibited in Figure 4. The results show that the fatigue life of specimen repaired by laser with addition of nanocomposite powder is higher than the fatigue life of which repaired by laser only regardless of probability level. However, with the load amplitude increases, the improvement of fatigue life is no longer obvious. It means that laser repair with addition of nanocomposite powder has a more significant effect on improving the life of high cycle fatigue. Meanwhile, the dispersion of test data also needs to be noticed, which reveal the instability of laser processing. 


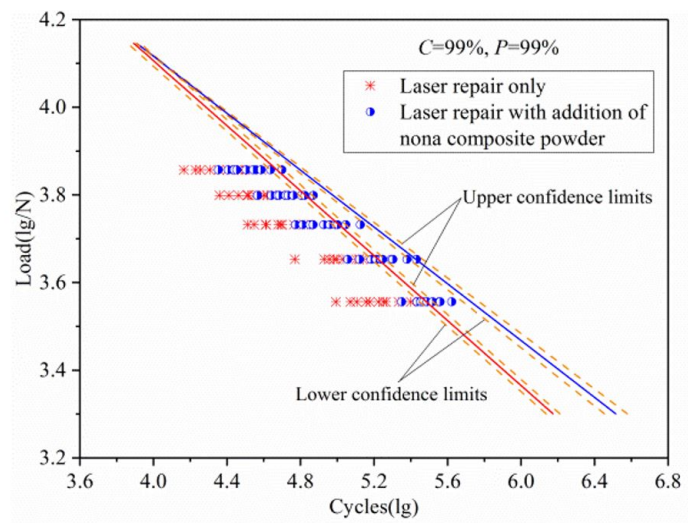

(a)

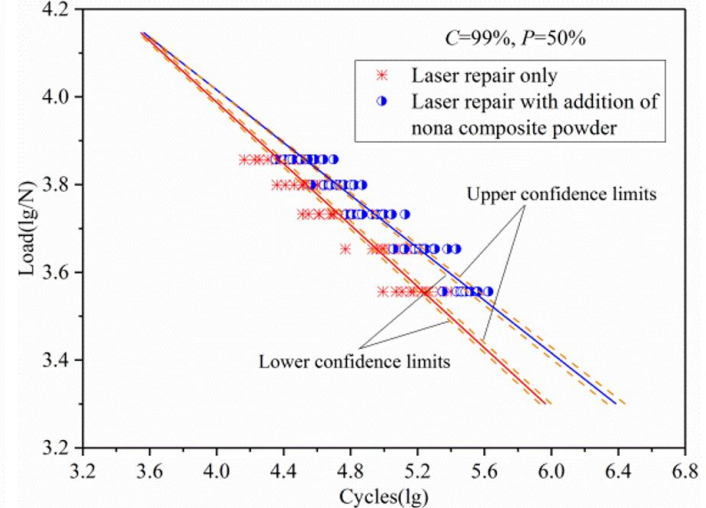

(b)

Figure 4. Probabilistic $S-N$ curves with $C=50 \%$ at specified $P$ levels, and the scatter points are test data. (a) $C=99 \%, P=99 \% ;(b) C=99 \%, P=50 \%$.

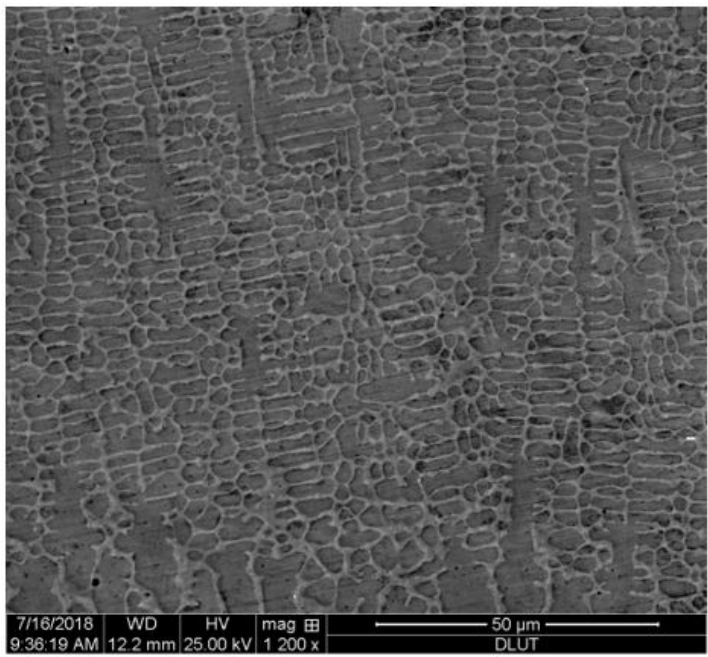

(a)

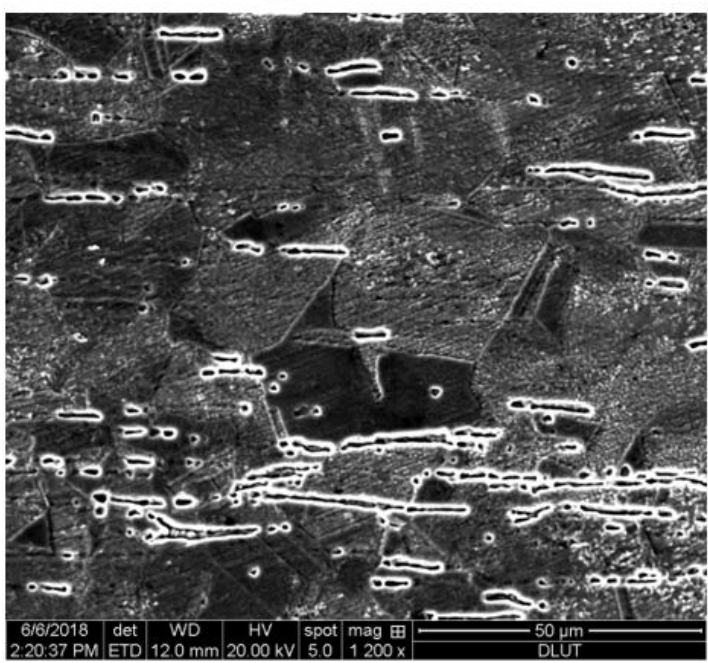

(c)

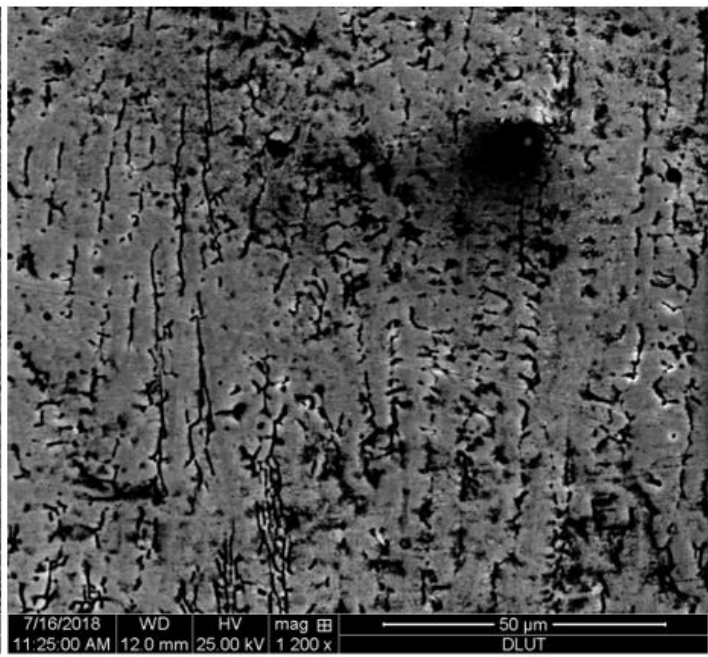

(b)

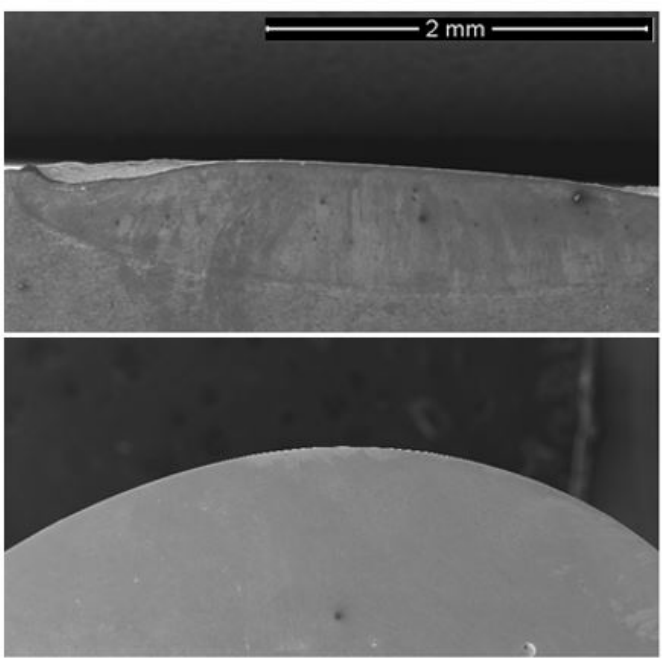

(d)

Figure 5. SEM microstructure of cross sections of repaired layer in the specimens and substrate (the scales are same). (a) laser repair with addition of nanocomposite powder; (b) laser repair only; (c) 304 stainless steel substrate; (d) The cross section of the specimen: the upper was repaired by laser only and the lower one repaired by laser with addition of powder. 
When the metal heated by laser is molten, the flow of molten metal in the molten pool makes the microcracks heal. In the process of metal solidification, the solidification of metal in high temperature molten pool was accelerated by the thermal conduction of substrate that results in the decrease of size of recrystallized grain, which can be obtained through the comparison of results shown in Figure 5b and Figure 5c. According to the Hall-Petch relation [17], the strength of alloy would be improved with the decrease of grain size. As the grain boundary will hinder the dislocation movement and reduce the stress concentration in the crystal, which would lead to the improvement of strength and toughness, that is, grain boundary strengthening [18]. The experimental results also showed that the specimen repaired by laser would lead to a rough surface of repaired region which may promote the initiation of microcracks, as shown in Figure 5d. However, the undissolved WC nanoparticles with high melting point can provide heterogeneous nucleation sites in the process of rapid solidification, which would result in a microstructure with uniform and fine equiaxial grains [19], as shown in Figure 5a. In addition, the use of nanoparticle additives in 304SS powders accelerates the diffusion of atoms and decreases the activation energy needed for densification, which would lead to high density and smooth surface and consequently resulting in enhanced fatigue life of specimens [20]. With the further increase of external load, the stress concentration at the crack tip would cause obvious plastic deformation in the vicinage of crack tip. However, the size of the repaired area as well as the ability of material to resist plastic deformation are limited, so the effect of laser repairing on the improvement of low cycle fatigue life is not obvious.

\section{Conclusion}

In this paper, the fatigue property of 304SS CT specimen repaired by laser was investigated. According to the fatigue test results, the probability $S-N$ curve considered the sampling size and scattered was established to evaluate the fatigue life of components. The results analysis show that the fatigue life of components repaired by laser with addition of nano WC composite powders was superior to the fatigue life of which repaired by laser only, in particular the improvement of high cycle fatigue life. The microstructure of repaired region also showed that the addition of nano WC composite powders will refine the recrystallized grain and result in the improvement of strength and toughness of material around crack tip. Meanwhile, the WC nanoparticles would promote the densification process and consequently increase the density, result in enhanced fatigue property. The smooth surface of repaired region caused by WC nanoparticles can also prevent the initiation of microcracks.

\section{Acknowledgements}

Project No. 51575076 supported by the National Natural Science Foundation of China is gratefully acknowledged.

\section{References}

[1] Dewei D, Jing Y, Qianqian L, Tao Y, Zhang H. States and prospects of crack arrest and healing technology. Journal of Mechanical Engineering, 2016,52(7):122-132.

[2] Ren XD, Zhou WF, Ren YP, Xu SD, Liu FF, Yuan SQ, et al. Dislocation evolution and properties enhancement of GH2036 by laser shock processing dislocation dynamic simulation and experiment. Materials Science and Engineering A. 2016;654:184-192. http://dx.doi.org/10.1016/j.msea.2015.12.007.

[3] Montross CS, Wei T, Ye L, Clark G, Yiu-Wing, M. Laser shock processing and its effects on microstructure and properties of metal alloys: a review. International Journal of Fatigue. 2002;24(10):1021-1036. http://dx.doi.org/10.1016/S0142-1123(02)00022-1.

[4] Zheng L, Zhang C, Zhang C, Dai F. Performance of micro-dent array fabricated by laser shock peening on the surface of A304 stainless steel. Vacuum. 2017;138:93-100. http://dx.doi.org/10.1016/j.vacuum.2017.01.021.

[5] Syed R, Jiang W, Wang C, Iqbal Sabir M. Fatigue life of stainless steel 304 enhancement by addition of multi-walled carbon nanotubes (MWCNTs). Journal of Mechanical Science and Technology. 2015;29(1):291-296. http://dx.doi.org/10.1007/s12206-014-1235-7.

[6] Ren XD, Zhang T, Zhang YK, Jiang DW, Yongzhuo HF, Guan HB, et al. Mechanical properties and residual stresses changing on $00 \mathrm{Cr} 12$ alloy by nanoseconds laser shock processing at high temperatures. Materials Science and Engineering A. 2011;528(4-5):1949-1953. http://dx.doi.org/10.1016/j.msea.2010.10.098.

[7] Zhang W, Picu RC, Koratkar N. Suppression of fatigue crack growth in carbon nanotube composites. Applied Physics Letters. 2007;91:193109. https://doi.org/10.1063/1.2809457.

[8] Jiang W, Jiang X. Laser repair with addition of nano-WC on microstructure and fracture behavior of 304 stainless steel. Journal of Engineering Materials and Technology. 2017;139(4):1-9. http://dx.doi.org/10.1115/1.4036586.

[9] D'Angelo L, Nussbaumer A. Estimation of fatigue S-N curves of welded joints using advanced probabilistic approach. International Journal of Fatigue. 2017;97:98-113. http://dx.doi.org/10.1016/j.ijfatigue.2016.12.032.

[10] Liu F, Zhou S, Xia C, Zeng D, Shi T. Optimization of fatigue life distribution model and establishment of probabilistic S-N curves for a 165 ksi grade super high strength drill pipe steel. Journal of Petroleum Science Engineering. 2016;145:527-532. http://dx.doi.org/10.1016/j.petrol.2016.06.018. 
[11] Yongxiang Z, Hongqin L. Modeling of the probabilistic fatigue S-N curves using the two parameter weibull distribution. Journal of Mechanical Engineering, 2015;51(20):208-212. http://dx.doi.org/10.3901/JME.2015.20.208.

[12] Zhao Y. A fatigue reliability analysis method including super long life regime. International Journal of Fatigue. 2012;35(1):79-90. http://dx.doi.org/10.1016/j.ijfatigue.2010.11.011.

[13] Zhao Y, Yang B. Probabilistic measurements of the fatigue limit data from a small sampling up-and-down test method. International Journal of Fatigue. 2008;30(12):2094-2103. http://dx.doi.org/10.1016/j.ijfatigue.2008.06.004.

[14] Zhao Y-X, Gao Q, Wang J-N. An approach for determining an appropriate assumed distribution of fatigue life under limited data. Reliability engineering and System Safety. 2000,67(1):1-7. https://doi.org/10.1016/S0951-8320(99)00036-8.

[15] American Society for Testing and Materials. ASTM E647-2013a: standard test method for measurement of fatigue crack growth rates. West Conshohocken: ASTM; 2013.

[16] Zhao YX, Liu HB. Weibull modeling of the probabilistic S-N curves for rolling contact fatigue. International Journal of Fatigue. 2014;66:47-54. http://dx.doi.org/10.1016/j.ijfatigue.2014.03.008.

[17] Hansen N. Hall-Petch relation and boundary strengthening. Scripta Materialia. 2004;51(8):801-806. http://dx.doi.org/10.1016/j.scriptamat.2004.06.002.

[18] Ganesh P, Kaul R, Paul CP, Tiwari P, Rai SK, Prasad RC, et al. Fatigue and fracture toughness characteristics of laser rapid manufactured Inconel 625 structures. Materials Science and Engineering A. 2010;527(29-30):7490-7497. http://dx.doi.org/10.1016/j.msea.2010.08.034.

[19] Zhang Y, Xu P, Liu C, Ren J, Gong H. The influence of carbides on the microstructure, grain growth, and oxidation resistance of nanostructured carbides-strengthened cobalt-based multi-track laser-cladding layers. Applied Surface Science. 2019;469:495-504. http://dx.doi.org/10.1016/j.apsusc.2018.11.084.

[20] Molina-Claros J, Hdz-García HM, Alvarez-Vera M, Pech-Canul MI, Muñoz-Arroyo R, García-Vázquez F, et al. Characterisation of PTA processed overlays without and with WC nanoparticles. Surface Engineering. 2017;33(11):857-865. http://dx.doi.org/10.1080/02670844.2017.1323442. 